\title{
Psychological factors and pain catastrophizing in men with chronic prostatitis/chronic pelvic pain syndrome (CP/CPPS): a meta-analysis
}

\author{
Xinfei Huang ${ }^{1 \#}$, Zhan Qin ${ }^{2 \#}$, Hongliang Cui ${ }^{3 \#}$, Jianhuai Chen ${ }^{1}$, Tao Liu ${ }^{1}$, Yongkang Zhu ${ }^{4}$, \\ Shaoying Yuan ${ }^{2}$
}

${ }^{1}$ Department of Andrology, Jiangsu Province Hospital of Chinese Medicine, Affiliated Hospital of Nanjing University of Chinese Medicine, Nanjing 210029, China; ${ }^{2}$ Department of Andrology, Guangdong Provincial Hospital of Chinese Medicine, Zhuhai 519015, China; ${ }^{3}$ Department of Urology, Nantong Hospital of Traditional Chinese Medicine, Nantong 226001, China; ${ }^{4}$ Department of General Surgery, Jiangsu Province Hospital of Chinese Medicine, Affiliated Hospital of Nanjing University of Chinese Medicine, Nanjing 210029, China

Contributions: (I) Conception and design: Y Zhu, S Yuan; (II) Administrative support: Y Zhu, S Yuan; (III) Provision of study materials or patients: J Chen, T Liu; (IV) Collection and assembly of data: J Chen, T Liu; (V) Data analysis and interpretation: X Huang, Z Qin, H Cui; (VI) Manuscript writing: All authors; (VII) Final approval of manuscript: All authors.

"These authors contributed equally to this work.

Correspondence to: Dr. Yongkang Zhu. Department of General Surgery, Jiangsu Province Hospital of Chinese Medicine, Affiliated Hospital of Nanjing University of Chinese Medicine, Nanjing 210029, China. Email: zhuyk8888@126.com; Dr. Shaoying Yuan. Department of Andrology, Guangdong Provincial Hospital of Chinese Medicine, Zhuhai 519015, China. Email: ysy017@126.com.

Background: Chronic prostatitis/chronic pelvic pain syndrome (CP/CPPS) is a chronic disease with a variety of psychosocial and somatic symptoms. CP/CPPS has substantial health care costs with unclear etiology, which may be caused by psychosocial factors. Moreover, previous studies suggested that cognitive processes played a crucial role in the perception of somatic pain. Therefore, the aim of this meta-analysis was to analyze the psychosocial characteristics in men with CP/CPPS, especially the symptom of pain catastrophizing.

Methods: Relevant publications were searched in different databases including PubMed, MEDLINE, EMBASE, Google Scholar and the Cochran Library using the search terms of "Chronic prostatitis", "Chronic pelvic pain syndrome", "Psychosocial" and "Catastrophizing". The prevalence of psychological factors and pain catastrophizing in men with CP/CPPS were extracted and calculated.

Results: Ten studies inclusive of 1,308 patients were included. Analysis of NIH-CPSI scores showed that the severity of CP/CPPS was 23.20 (95\% CI: 21.13-25.28). The severity of pain catastrophizing was 13.81 (95\% CI: 9.83-17.79) estimated by coping strategies questionnaire (CSQ), while the severity of pain catastrophizing was 24.83 (95\% CI: 9.19-40.47) estimated by pain catastrophizing scale (PCS). The prevalence of psychosocial symptom was 0.43 (95\% CI: $0.32-0.55$ ), while the prevalence of pain catastrophizing was 0.26 (95\% CI: 0.21-0.31).

Conclusions: The psychological factors and pain catastrophizing in men with CP/CPPS was serious. Furthermore, the prevalence of psychosocial symptom and pain catastrophizing was high. There might be a link between pain catastrophizing and somatic symptoms in CPPS. Thus, further prospective studies are needed to evaluate the importance of psychosocial factors in symptom severity of CP/CPPS.

Keywords: Chronic prostatitis (CP); chronic pelvic pain syndrome (CPPS); psychosocial; catastrophizing; metaanalysis

Submitted Sep 19, 2019. Accepted for publication Jan 04, 2020.

doi: $10.21037 /$ tau.2020.01.25

View this article at: http://dx.doi.org/10.21037/tau.2020.01.25 


\section{Introduction}

Chronic prostatitis/chronic pelvic pain syndrome (CP/ CPPS) is a chronic disease characterized by a number of symptoms (1). The most common symptom of CP/ CPPS is pain, which may be persistent or occur in in numerous locations (2). Moreover, psychosocial factors or psychiatric comorbidities are frequent among patients with CP/CPPS, which has severe impact on the quality of life (QoL) for male patients (3). Due to the heterogeneity and multifactorial etiology of CP/CPPS, single treatment was less effective than multimodal therapy approaches, especially for male patients with numerous psychosocial variables (4). Psychosocial factors, such as pain catastrophizing, were associated with the difficult in the management of CP/ CPPS symptoms and the poorer QoL (5).

The symptoms of CP/CPPS are mostly evaluated by the method of the National Institutes of Health-Chronic Prostatitis Symptom Index (NIH-CPSI) with limitation of not assessing psychological factors, which are very common in CP/CPPS patients (6). UPOINT was developed by Shoskes et al., which contained the clinical domain of psychosocial dysfunction (7). Previous study showed that men with CP/CPPS suffered from a high burden of psychosocial symptoms, had poor adjustment, which lead to greater pain, more disability and diminished mental QoL (8). In addition, greater pain catastrophizing was correlated with higher UPOINT scores, higher pain scores, worse urinary function and worse QoL in CP/CPPS patients (9). Pain catastrophizing (ruminative, magnifying, helpless about pain) was considered to play a crucial role in chronic pain and might be associated with the chronic pelvic pain of $\mathrm{CP} /$ CPPS patients (10).

The severity of psychological factors has been reported to be associated with individual stress perception or subjective stress interpretation of CP/CPPS patients (11). For CP/CPPS patients, individual coping strategies and cognitive assessment about the contents or frequency of the causative factors, played a vital role in the occurrence and progression of stress (12). Abnormal coping strategies and cognitive assessment might cause stress or psychological factors, even physical diseases of CP/CPPS patients (13). Moreover, psychotherapeutic management might be a useful tool for the clinical treatment of CP/CPPS patients who were refractory to drug therapy or physiotherapy (14).

Despite some studies of the relationships between psychological factors (such as depression and pain catastrophizing) and the development, prolongation of the symptoms in CP/CPPS patients (3), there is lack of knowledge about the severity of psychological factors and the prevalence of pain catastrophizing in patients. And the deeper understanding of the association between the psychological mechanisms and the heterogeneity of symptoms, was crucial for the improved therapies for CP/ CPPS patients.

This meta-analysis will summarize and synthesize the severity and the prevalence of psychological factors and pain catastrophizing in CP/CPPS patients, to further understand the role of psychosocial factors and pain catastrophizing in the development and maintenance of CP/CPPS. Moreover, all these results will contribute to the development of the effective approaches to improve the pain symptom, urinary function, QoL, psychological factors and psychiatric comorbidities in CP/CPPS patients.

\section{Methods}

Prior to the literature search, participants, interventions, comparisons, outcomes, and study design (PICOS) items were defined: P: patients were diagnosed with CP/CPPS by the NIH classification or patients met the traditional definition of CP prostatodynia/nonbacterial prostatitis. I: not applicable. C: the psychological factors and pain catastrophizing of patients. O: the severity or the prevalence of psychological factors and pain catastrophizing of patients. S: cross-sectional studies.

The review was developed according to Preferred Reporting Items for Systematic Reviews and Meta-Analyses (PRISMA).

\section{Search strategy}

We searched relevant publications that investigated the severity or prevalence of psychological factors and pain catastrophizing in CP/CPPS patients. Studies that investigated the severity or prevalence of psychological factors and pain catastrophizing in CP/CPPS patients were selected through a standard search in the PubMed, Medline, Google Scholar, the Cochrane library and Embase until October 2018. We performed the search by the following keywords or expressions: "Chronic prostatitis", "Chronic pelvic pain syndrome", "Psychosocial" and "Catastrophizing". All possible combinations of keywords were used as search terms to identify all possible candidates. And the final searching strategies were as follow: (Chronic 
prostatitis $[\mathrm{MeSH}]$ OR Chronic pelvic pain syndrome $[\mathrm{MeSH}])$ AND (Psychosocial [MeSH] OR Catastrophizing $[\mathrm{MeSH}])$. Article types were restricted to cross-sectional english studies.

The abstract of all potentially relevant studies was screened and then full articles were also reviewed if the abstract were indistinct. In addition, the reference lists of relevant articles were retrieved. ALL articles that investigated the severity or the prevalence of psychological factors and pain catastrophizing CP/CPPS patients were restricted in our meta-analysis.

\section{Inclusion criteria}

The included articles should meet the following inclusion criteria: (I) patients were diagnosed with CP/CPPS by the NIH classification or patients met the traditional definition of CP prostatodynia/nonbacterial prostatitis; (II) studies that investigated the severity or the prevalence of psychological factors and pain catastrophizing of patients; (III) sufficient data of the severity of psychological factors or the prevalence of pain catastrophizing could be extracted; (IV) the severity of disease and psychological factors were assessed by National Institutes of Health Chronic Prostatitis Symptom Index (NIH-CPSI), Coping Strategies Questionnaire (CSQ) or Pain Catastrophizing Scale (PCS).

\section{Exclusion criteria}

We excluded studies that (I) were case reports; (II) included patients with other prostatitis syndromes; (III) involved patients diagnosed with other disorders of the urogenital system; (IV) had insufficient data about the psychological factors.

\section{Data extraction and quality assessment}

The demographic of all included articles was extracted, including first author, year of publication, sample size, age of patients, evaluation tools and symptom duration. In addition, outcome data of psychological factors were also were extracted from the studies, including (I) the scores of NIH-CPSI (the severity of CP/CPPS), (II) CSP (the severity of pain catastrophizing), (III) the percentage of psychosocial factors, (IV) the percentage of pain catastrophizing.
The quality was assessed by two authors (Xinfei Huang and Jianhuai Chen) with the method of Agency for Health care Research and Quality (AHRQ). AHRQ recommends 11 items and the Crombie's items contains 7 items for assessing the quality of cross-sectional/ prevalence study. Differences in assessment were solved through a discussion with another author (Yun Chen).

\section{Statistical analysis}

The mean and standard deviation of the scores of NIHCPSI, CSQ and PCS were derived, as well as the prevalence of psychosocial factors and pain catastrophizing. The results of meta-analysis, including the scores of NIH-CPSI, CSQ, PCS and the prevalence of psychosocial problem and pain catastrophizing, were presented with standardized mean differences (SMD), which were identified by $95 \%$ CI. Heterogeneity was assessed with $\chi^{2}$ and $\mathrm{I}^{2}$ statistic (15). The pooled effect was calculated by the random effect model if there was statistically significant heterogeneity ( $\mathrm{P}$ was less than 0.1 or I2 was greater than $50 \%$ ); otherwise, the fixedeffect model was conducted. The probability of publication bias was assessed by Egger's (16) and Begg-Mazumdar (17) test. $\mathrm{P}<0.05$ was considered statistically significant.

\section{Results}

\section{Literature search results}

A total of 103 relevant articles were identified by literature search. Then 84 records were removed after screening the titles and abstract of each study. And 3 studies were removed as they did not provide the data of the severity or percentage of pain catastrophizing. Six articles were removed owing to the lack of information about the psychological factors. Finally, 10 articles satisfied the inclusion criteria were included in our meta-analysis. The flowchart of the selection process was presented in Figure 1.

\section{Characteristics of included trials}

We included 10 studies that explored the severity or prevalence of psychological factors or pain catastrophizing, which included male 1,308 patients with CP/CPPS. Three studies were included for reporting the prevalence of pain catastrophizing. Five studies evaluated the prevalence of psychological factors and 7 articles reported the severity 


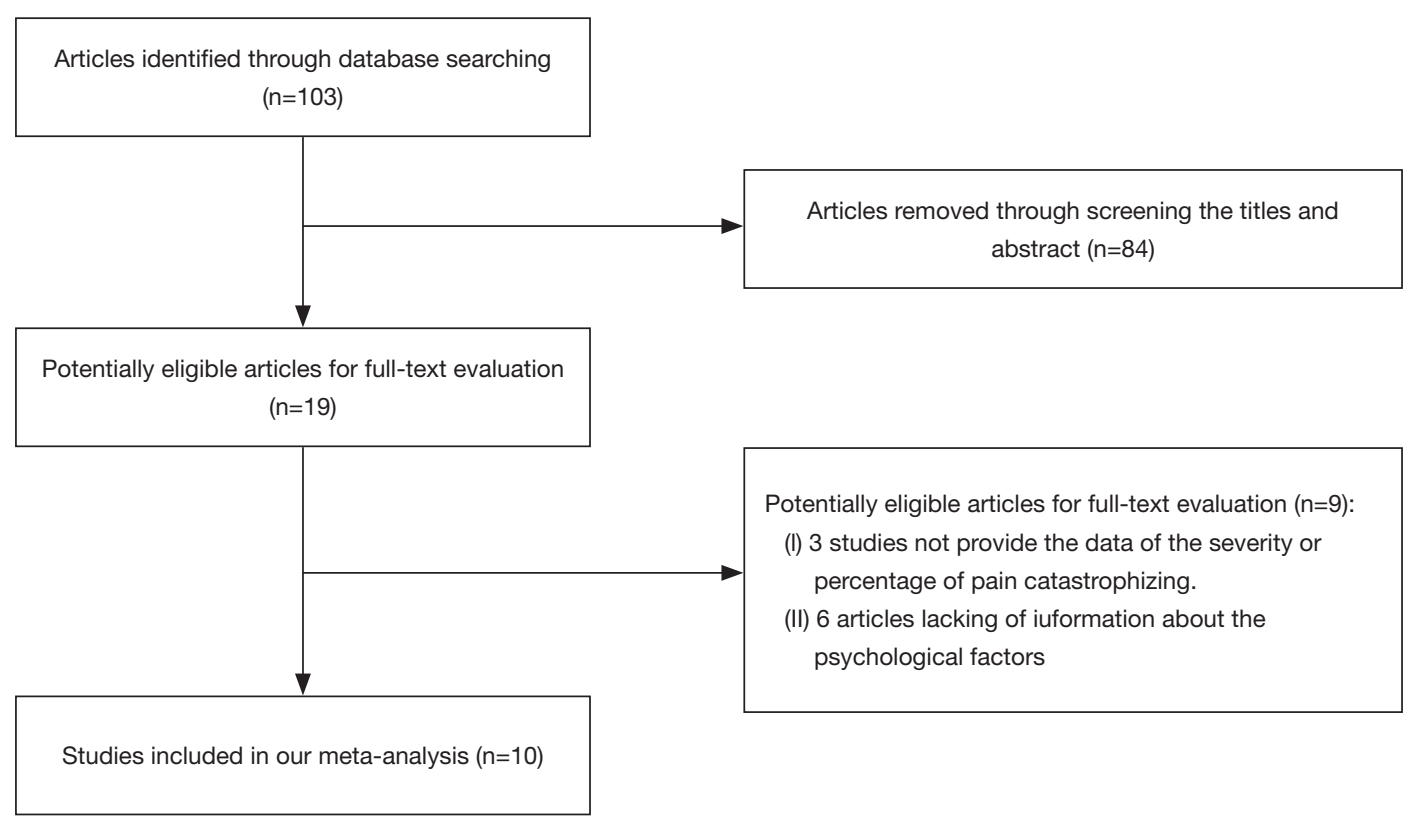

Figure 1 Flow diagram of selection of eligible studies.

of pain catastrophizing. Detailed characteristics of all the included studies were summarized in Table 1.

\section{Meta-analysis}

\section{Severity of CP/CPPS}

Nine studies reported the scores of NIH-CPSI of CP/ CPPS patients. The pooled estimation for the severity of disease among men patients with CP/CPPS was 23.20 (95\% CI: 21.13-25.28) by the random effect model (Figure 2). In addition, significant heterogeneity was observed $\left(I^{2}=96 \%\right.$; $\mathrm{P}<0.01)$. No significant was found about the publication bias assessed by Egger's $(\mathrm{P}>0.05)$ and Begg-Mazumdar test $(\mathrm{P}>0.05)$.

\section{Severity of pain catastrophizing}

Seven studies collected the scores of CSQ or PCS to assess the severity of pain catastrophizing. The results demonstrated that the pooled estimation was 13.81 (Random-effects model; 95\% CI: 9.83-17.79; Figure 3) estimated by CSQ and 24.83 (Random-effects model; 95\% CI: 9.19-40.47; Figure 4) estimated by PCS for the severity of pain catastrophizing in patients with CP/CPPS with significant heterogeneity $\left(\mathrm{I}^{2}=91 \%, \mathrm{P}<0.01 ; \mathrm{I}^{2}=100 \%\right.$, $\mathrm{P}<0.01)$. No evidences of publication bias were found by
Egger's $(\mathrm{P}>0.05)$ and Begg-Mazumdar test $(\mathrm{P}>0.05)$.

\section{Prevalence of psychological factors}

With the random effect model, the pooled SMD for the prevalence of psychological factors in 5 studies was 0.43 (95\% CI: 0.32-0.55; Figure 5). There was significant heterogeneity among these studies $\left(\mathrm{I}^{2}=88 \% ; \mathrm{P}<0.01\right)$. Egger's $(\mathrm{P}>0.05)$ and Begg-Mazumdar test $(\mathrm{P}>0.05)$ did not reveal evidences of publication bias.

\section{Prevalence of pain catastrophizing}

Three studies reported the data about the prevalence of pain catastrophizing. As shown in Figure 6, pooled estimation for the prevalence of pain catastrophizing in men patients with CP/CPPS was 0.26 (Fixed-effects model; 95\% CI: $0.21-0.31)$ with significant heterogeneity $\left(\mathrm{I}^{2}=0 \% ; \mathrm{P}=0.74\right)$. Evidences of publication bias were not observed Egger's $(\mathrm{P}>0.05)$ and Begg-Mazumdar test $(\mathrm{P}>0.05)$.

\section{Discussion}

This is the first meta-analysis that explored the psychosocial characteristics in men patients with CP/CPPS, including the severity and prevalence of psychological factors and pain catastrophizing. The results demonstrated that 
Table 1 Characteristics of the included trials

\begin{tabular}{|c|c|c|c|c|c|c|c|c|c|}
\hline Author & Year & $\begin{array}{l}\text { Sample } \\
\text { size }\end{array}$ & Age (years) & $\begin{array}{l}\text { Evaluation } \\
\text { tools }\end{array}$ & Symptom duration & $\mathrm{NIH}-\mathrm{CPSI}$ & $\begin{array}{l}\text { Catastrophizing } \\
\text { scores }\end{array}$ & $\begin{array}{l}\text { Percentage of } \\
\text { psychosocial }^{\text {a }}\end{array}$ & $\begin{array}{l}\text { Percentage of } \\
\text { catastrophizing } \\
\text { (criterion) }\end{array}$ \\
\hline $\begin{array}{l}\text { Samplaski MK } \\
\text { (19) }\end{array}$ & 2012 & $220^{\mathrm{b}}$ & $44.6 \pm 13.4$ & $\begin{array}{l}\text { NIH-CPSI, } \\
\text { UPOINT }\end{array}$ & $\begin{array}{l}57.05 \pm 87.49 \\
\text { months }\end{array}$ & $25.02 \pm 6.49$ & NA & $83(33.7 \%)^{c}$ & $25(25 \%)^{d}(N A)$ \\
\hline Hedelin HH (20) & 2009 & 50 & $46[26-71]$ & $\begin{array}{l}\text { NIH-CPSI, } \\
\text { CSQ, } \\
\text { UPOINT }\end{array}$ & $\begin{array}{c}7 \text { years }(6 \text { months - } \\
35{\text { years })^{e}}^{\text {en }}\end{array}$ & $23 \pm 7$ & $16.09 \pm 9.5(\mathrm{CSQ})$ & $18(36 \%)$ & $\begin{array}{c}15(30 \%)(\mathrm{CSQ} \\
\geq 21)\end{array}$ \\
\hline $\begin{array}{l}\text { Polackwich AS } \\
(21)\end{array}$ & 2015 & 82 & $41.6 \pm 13.2$ & $\begin{array}{l}\text { NIH-CPSI, } \\
\text { UPOINT }\end{array}$ & 24 [3-240] months & $26.8 \pm 6.3$ & NA & $39(47.60 \%)$ & NA \\
\hline Zhang YD (22) & 2016 & 192 & 31.3 [18-57] & $\begin{array}{l}\text { NIH-CPSI, } \\
\text { PCS, } \\
\text { UPOINT }\end{array}$ & 20.5 [3-165] months & $20.5 \pm 6.9$ & $\begin{array}{c}11.10 \pm 10.70 \\
\text { (PCS) }\end{array}$ & 115 (59.90\%) & NA \\
\hline Davis SNP (23) & 2013 & 171 & $\begin{array}{c}44.2 \pm 14.0 \\
{[18-82]}\end{array}$ & $\begin{array}{l}\text { NIH-CPSI, } \\
\text { PCS, } \\
\text { UPOINT }\end{array}$ & $56.7 \pm 24$ months & $24.1 \pm 7.24$ & $\begin{array}{c}23.30+12.40 \\
\text { (PCS) }\end{array}$ & NA & NA \\
\hline $\begin{array}{l}\text { Krsmanovic A } \\
\text { (2) }\end{array}$ & 2014 & 175 & $46.83 \pm 10.86$ & $\begin{array}{l}\text { NIH-CPSI, } \\
\text { PCS }\end{array}$ & $\begin{array}{c}\text { At least } 3 \text { of the last } \\
6 \text { months }\end{array}$ & $16.47 \pm 8.67$ & $\begin{array}{c}16.30 \pm 9.52 \\
\text { (PCS) }\end{array}$ & NA & NA \\
\hline Naliboff BD (24) & 2017 & 176 & $47.7 \pm 15.5$ & $\begin{array}{l}\text { NIH-CPSI, } \\
\text { PCS, CSQ }\end{array}$ & $8.1 \pm 10.9$ years & NA & $\begin{array}{c}50.0 \pm 9.10 \\
\text { (PCS), } 10.4 \pm 8.5 \\
\text { (CSQ) }\end{array}$ & NA & NA \\
\hline
\end{tabular}

a , according to UPOINT; ${ }^{b}, 120$ patients were characterized by UPOINT and 100 patients were characterized by its subdomain; ${ }^{\mathrm{c}}$, among the all the patients [220]; ${ }^{d}$, among the 100 patients characterized by the subdomain of UPOINT; ${ }^{e}, 20 \%$ had a history of less than 1 year. $\mathrm{NIH}-\mathrm{CPSI}$, National Institutes of Health Chronic Prostatitis Symptom Index; CSQ, Coping Strategies Questionnaire; PCS, Pain Catastrophizing Scale.

CP/CPPS patients suffered from high prevalence of psychosocial factors or psychiatric comorbidities, while pain catastrophizing was significant in the patients with psychological factors. All these findings were consistent with other researches, which showed that psychological factors, especially pain catastrophizing, might significantly affect the urological and nonurological conditions, including pain and QoL of patients, as well as the treatment $(26,27)$.

There was a complex interaction between psychopathologic and somatic symptoms (26). Previous study showed that high psychosocial burden was found in CP/CPPS patients (27). Meanwhile, painful point of CP/CPPS was related with the self-reported psychosocial factors (28). Moreover, high rates of psychopathologic factors or symptoms might lead to lower QoL (2). The results of our meta-analysis indicated that both high prevalence of psychosocial problem and pain catastrophizing was found in CP/CPPS patients. The serious mental disorders, especially depression anxiety and stress, and high prevalence of pain catastrophizing, might influence the severity of disease, the symptoms, treatment and prognosis of men suffering from CP/CPPS $(29,30)$.

Previous study demonstrated that abnormal cognition could lead to pain-related disability, while catastrophizing, including rumination magnification and helplessness, made a significant contribution to the inability to disengage from negative pain ruminations (3). Pain was the most common 


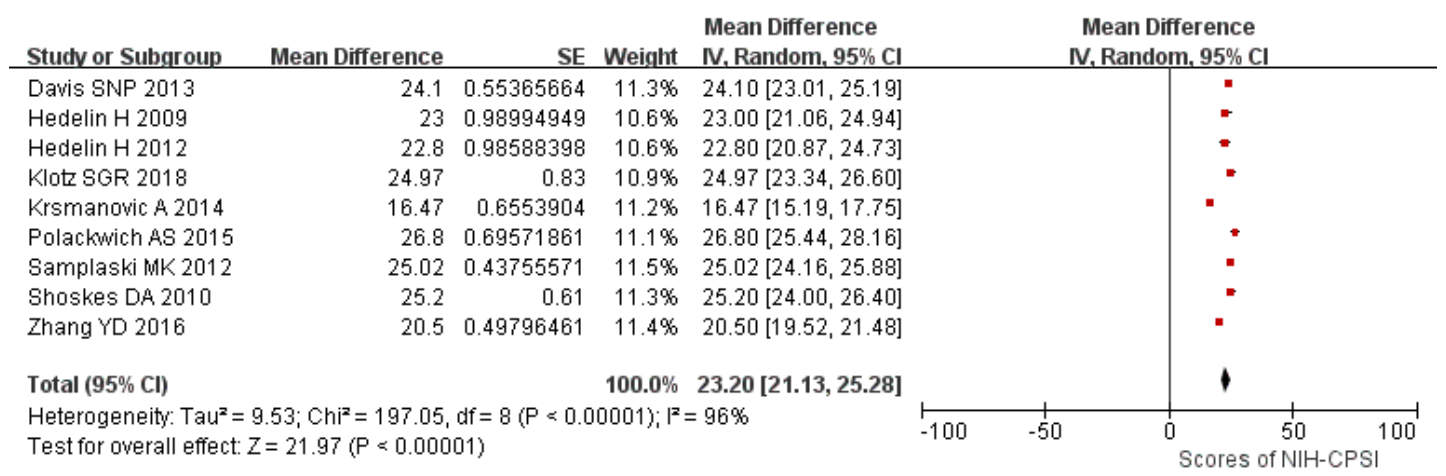

Figure 2 Overall severity of the disease among men patients with chronic prostatitis/chronic pelvic pain syndrome (CP/CPPS).

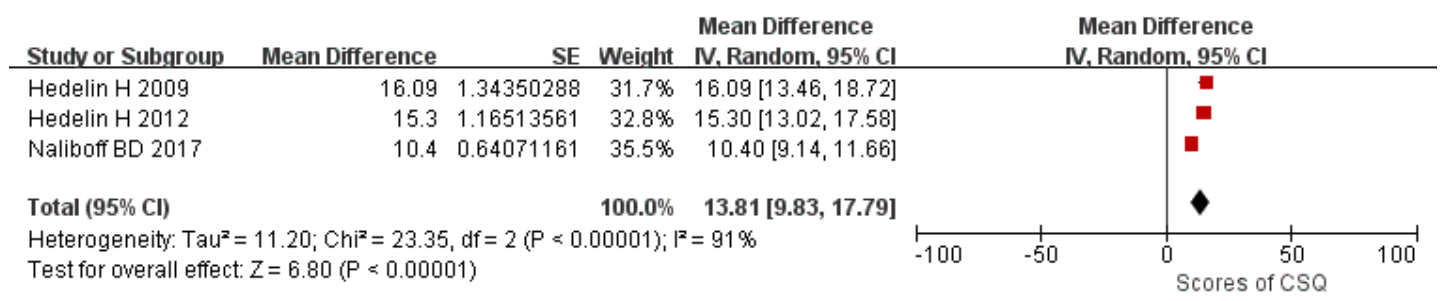

Figure 3 Overall severity of pain catastrophizing estimated by coping strategies questionnaire (CSQ) among men patients with chronic prostatitis/chronic pelvic pain syndrome (CP/CPPS).

\begin{tabular}{|c|c|c|c|c|c|c|c|c|c|}
\hline Study or Subgroup & Mean Difference & SE & Weight & $\begin{array}{l}\text { Mean Difference } \\
\text { IV, Random, } 95 \% \mathrm{Cl}\end{array}$ & \multicolumn{5}{|c|}{$\begin{array}{l}\text { Mean Difference } \\
\text { N, Random, } 95 \% \mathrm{Cl}\end{array}$} \\
\hline Davis SNP 2013 & 23.3 & 0.9482517 & $20.0 \%$ & $23.30[21.44,25.16]$ & & & $=$ & & \\
\hline Klotz SGR 2018 & 23.44 & 1.43666667 & $19.9 \%$ & $23.44[20.62,26.26]$ & & & $=$ & & \\
\hline Krsmanovic A 2014 & 16.3 & 0.71964436 & $20.0 \%$ & $16.30[14.89,17.71]$ & & & - & & \\
\hline Naliboff BD 2017 & 50 & 0.68593831 & $20.0 \%$ & $50.00[48.66,51.34]$ & & & & - & \\
\hline Zhang YD 2016 & 11.1 & 0.77220598 & $20.0 \%$ & $11.10[9.59,12.61]$ & & & - & & \\
\hline Total $(95 \% \mathrm{Cl})$ & & & $100.0 \%$ & $24.83[9.19,40.47]$ & & & & & \\
\hline \multicolumn{5}{|c|}{$\begin{array}{l}\text { Heterogeneity: } \operatorname{Tau}^{2}=317.45 ; \mathrm{Chi}^{2}=1788.21, \mathrm{df}=4(\mathrm{P}<0.00001) ; \mathrm{I}^{2}=100 \% \\
\text { Test for overall effect: } Z=3.11(P=0.002)\end{array}$} & -100 & -50 & Scores 0 & $\begin{array}{c}50 \\
\mathrm{f} P \mathrm{CS}\end{array}$ & 100 \\
\hline
\end{tabular}

Figure 4 Overall severity of pain catastrophizing estimated by pain catastrophizing scale (PCS) among men patients with chronic prostatitis/ chronic pelvic pain syndrome (CP/CPPS).

symptom in CP/CPPS patients, which was associated with the poor QoL of patients (10). Moreover, catastrophizing was robustly associated with the self-reported pain (31). Higher level of pain catastrophizing was found in CP/CPPS patients in the previous study (12). Our results also revealed high prevalence of pain catastrophizing in CP/CPPS patients. Pain-coping strategy was found to be associated with the outcome of CP/CPPS patients and it could be a predictor for the pain and other symptoms of patients (13).

It was important to note that reductions in psychosocial problem and pain catastrophizing might be associated with improvement in the urinary function, pain symptom, QoL in CP/CPPS patients (3). Less pain, depressive symptoms and better physical QoL could be predicted by the normal cognition and coping strategy (32,33). Cognitive factors play a vital role in patient adjustment, including helplessness catastrophizing and pain catastrophizing $(34,35)$. Therefore, biopsychosocial treatment model including psychotherapeutic management should be developed for men patients with CP/CPPS who are refractory to drug 


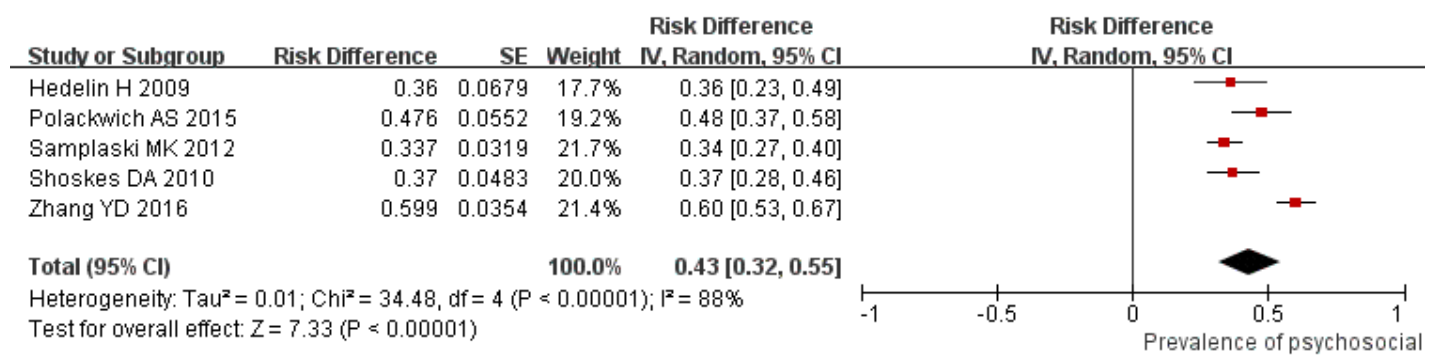

Figure 5 Overall prevalence of psychological factors among men patients with chronic prostatitis/chronic pelvic pain syndrome (CP/CPPS).

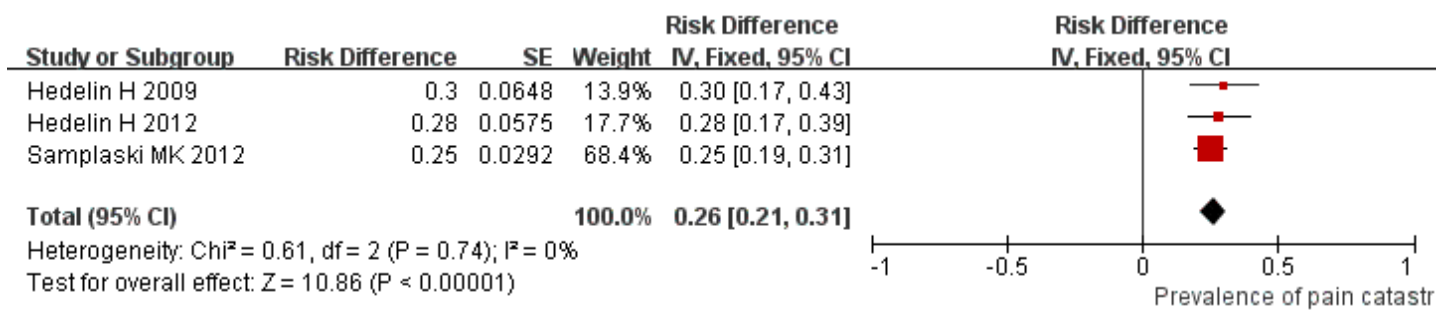

Figure 6 Overall prevalence of pain catastrophizing among men patients with chronic prostatitis/chronic pelvic pain syndrome (CP/CPPS).

therapy and physiotherapy.

However, some limitations of this meta-analysis should be addressed. First, the number of included studies is insufficient, and some studies have a relatively small sample size. Second, there were differences among participants and methods, including differences in durations. In addition, we were unable to analyze the association between the severity of CP/CPPS and psychosocial symptoms.

\section{Conclusions}

This meta-analysis showed that men patients with CPPS in this study suffered from a high burden of psychosocial symptoms, especially pain catastrophizing. More researches about the psychosocial symptoms in CP/CPPS were needed to explore the relationships between the psychosocial problem including abnormal cognition, coping strategy and urinary function, pain, QoL of CP/CPPS patients, and to develop multimodal management for patients suffering from a high burden of psychopathologic and somatic symptoms.

\section{Acknowledgments}

Funding: This study was supported by the Jiangsu Province Six Talent Peaks Project (2015-WSN-050); “333” Project of Jiangsu Province (LGY2016016).

\section{Footnote}

Conflicts of Interest: All authors have completed the ICMJE uniform disclosure form (available at http://dx.doi. org/10.21037/tau.2020.01.25). The authors have no conflicts of interest to declare.

Ethical Statement: The authors are accountable for all aspects of the work in ensuring that questions related to the accuracy or integrity of any part of the work are appropriately investigated and resolved.

Open Access Statement: This is an Open Access article distributed in accordance with the Creative Commons Attribution-NonCommercial-NoDerivs 4.0 International License (CC BY-NC-ND 4.0), which permits the noncommercial replication and distribution of the article with the strict proviso that no changes or edits are made and the original work is properly cited (including links to both the formal publication through the relevant DOI and the license). See: https://creativecommons.org/licenses/by-ncnd/4.0/.

\section{References}

1. Anderson RU, Wise D, Nathanson BH. Chronic Prostatitis 
and/or Chronic Pelvic Pain as a Psychoneuromuscular Disorder-A Meta-analysis. Urology 2018;120:23-9.

2. Krsmanovic A, Tripp DA, Nickel JC, et al. Psychosocial mechanisms of the pain and quality of life relationship for chronic prostatitis/chronic pelvic pain syndrome (CP/ CPPS). Can Urol Assoc J 2014;8:403-8.

3. Riegel B, Bruenahl CA, Ahyai S, et al. Assessing psychological factors, social aspects and psychiatric comorbidity associated with Chronic Prostatitis/Chronic Pelvic Pain Syndrome (CP/CPPS) in men-a systematic review. J Psychosom Res 2014;77:333-50.

4. Magistro G, Wagenlehner FME, Grabe M, et al. Contemporary management of chronic prostatitis/chronic pelvic pain syndrome. Eur Urol 2016;69:286-97.

5. Polackwich AS, Shoskes DA. Chronic prostatitis/chronic pelvic pain syndrome: a review of evaluation and therapy. Prostate Cancer Prostatic Dis 2016;19:132-8.

6. Litwin MS, McNaughton-Collins M, Fowler FJ Jr, et al. The National Institutes of Health chronic prostatitis symptom index: development and validation of a new outcome measure. J Urol 1999;162:369-75.

7. Shoskes DA, Nickel JC, Kattan MW. Phenotypically directed multimodal therapy for chronic prostatitis/ chronic pelvic pain syndrome: a prospective study using UPOINT. Urology 2010;75:1249-53.

8. Nickel JC, Tripp DA, Chuai S, et al. Psychosocial variables affect the quality of life of men diagnosed with chronic prostatitis/chronic pelvic pain syndrome. BJU Int 2008;101:59-64.

9. Kwon JK, Chang IH. Pain, catastrophizing, and depression in chronic prostatitis/chronic pelvic pain syndrome. Int Neurourol J 2013;17:48-58.

10. Tripp DA, Curtis Nickel J, Landis JR, et al. Predictors of quality of life and pain in chronic prostatitis/chronic pelvic pain syndrome: findings from the National Institutes of Health Chronic Prostatitis Cohort Study. BJU Int 2004;94:1279-82.

11. Ahn SG, Kim SH, Chung KI, et al. Depression, anxiety, stress perception, and coping strategies in korean military patients with chronic prostatitis/chronic pelvic pain syndrome. Korean J Urol 2012;53:643-8.

12. Tripp DA, Nickel JC, Wang Y, et al. Catastrophizing and pain-contingent rest predict patient adjustment in men with chronic prostatitis/chronic pelvic pain syndrome. J Pain 2006;7:697-708.

13. Nickel JC, Mullins C, Tripp DA. Development of an evidence-based cognitive behavioral treatment program for men with chronic prostatitis/chronic pelvic pain syndrome.
World J Urol 2008;26:167-72.

14. Cohen JM, Fagin AP, Hariton E, et al. Therapeutic intervention for chronic prostatitis/chronic pelvic pain syndrome (CP/CPPS): a systematic review and metaanalysis. PLoS One 2012;7:e41941.

15. Higgins JPT, Thompson SG, Deeks JJ, et al. Measuring inconsistency in meta-analyses. BMJ 2003;327:557-60.

16. Egger M, Smith GD, Schneider M, et al. Bias in metaanalysis detected by a simple, graphical test. BMJ 1997;315:629-34.

17. Begg CB, Mazumdar M. Operating characteristics of a rank correlation test for publication bias. Biometrics 1994 ;50:1088-101.

18. Hedelin H. The chronic prostatitis/chronic pelvic pain syndrome and pain catastrophizing: a vicious combination. Scand J Urol Nephrol 2012;46:273-8.

19. Samplaski MK, Li J, Shoskes DA. Clustering of UPOINT domains and subdomains in men with chronic prostatitis/ chronic pelvic pain syndrome and contribution to symptom severity. J Urol 2012;188:1788-93.

20. Hedelin HH. Evaluation of a modification of the UPOINT clinical phenotype system for the chronic pelvic pain syndrome. Scand J Urol Nephrol 2009;43:373-6.

21. Polackwich AS, Li J, Shoskes DA. Patients with pelvic floor muscle spasm have a superior response to pelvic floor physical therapy at specialized centers. J Urol 2015;194:1002-6.

22. Zhang Y, Zheng T, Tu X, et al. Erectile dysfunction in chronic prostatitis/chronic pelvic pain syndrome: Outcomes from a multi-center study and risk factor analysis in a single center. PLoS One 2016;11:e0153054.

23. Davis SNP, Binik YM, Amsel R, et al. A subtype based analysis of urological chronic pelvic pain syndrome in men. J Urol 2013;190:118-23.

24. Naliboff BD, Stephens AJ, Lai HH, et al. Clinical and psychosocial predictors of urological chronic pelvic pain symptom change in 1 Year: a prospective study from the MAPP Research Network. J Urol 2017;198:848-57.

25. Klotz SGR, Ketels G, Löwe B, et al. Myofascial Findings and Psychopathological Factors in Patients with Chronic Pelvic Pain Syndrome. Pain Med 2020;21:e34-44.

26. Occhini J, Castellini G, Frederick CWW, et al. The relationship between depression and lower urinary tract symptoms is moderated by adverse life events and mediated by inflammatory mechanisms. Eur Neuropsychopharm 2017;27:S625.

27. Hao Z, Gao J, Zhou Z, et al. Symptoms, sexual dysfunction and psychological burden in Chinese men with chronic 
prostatitis/chronic pelvic pain syndrome. Int J Clin Exp Med 2016;9:4372-9.

28. Dybowski C, Löwe B, Brünahl C. Predictors of pain, urinary symptoms and quality of life in patients with chronic pelvic pain syndrome (CPPS): A prospective 12-month follow-up study. J Psychosom Res 2018;112:99-106.

29. Anderson RU, Orenberg EK, Morey A, et al. Stress induced hypothalamus-pituitary-adrenal axis responses and disturbances in psychological profiles in men with chronic prostatitis/chronic pelvic pain syndrome. J Urol 2009; 182:2319-24.

30. Anderson RU, Orenberg EK, Chan CA, et al. Psychometric profiles and hypothalamic-pituitary-adrenal axis function in men with chronic prostatitis/chronic pelvic pain syndrome. J Urol 2008;179:956-60.

31. Romano JM, Molton IR, Alschuler KN, et al. Reported pain and fatigue behaviors mediate the relationship between catastrophizing and perceptions of solicitousness in patients with chronic fatigue. J Pain 2016;17:328-35.

32. Ilves OE, Hermsen LAH, van der Wouden JC, et al. Are changes in pain, cognitive appraisals and coping strategies associated with changes in physical functioning in older adults with joint pain and chronic diseases? Aging Clin Exp Res 2019;31:377-83.

33. Hermsen LAH, van der Wouden JC, Leone SS, et al. The longitudinal association of cognitive appraisals and coping strategies with physical functioning in older adults with joint pain and comorbidity: a cohort study. BMC Geriatr 2016;16:29.

34. Davies B, Cramp F, Gauntlett-Gilbert J, et al. The role of physical activity and psychological coping strategies in the management of painful diabetic neuropathy-A systematic review of the literature. Physiotherapy 2015;101:319-26.

35. Litt MD, Tennen H. What are the most effective coping strategies for managing chronic pain? Pain Manag 2015;5:403-6.

Cite this article as: Huang X, Qin Z, Cui H, Chen J, Liu T, Zhu Y, Yuan S. Psychological factors and pain catastrophizing in men with chronic prostatitis/chronic pelvic pain syndrome (CP/CPPS): a meta-analysis. Transl Androl Urol 2020;9(2):485493. doi: 10.21037/tau.2020.01.25 